ISSN: 1980-055X

Recebido em: 07/03/2010

Aceito para publicação em: 19/07/2010

\title{
ILHAS DE CALOR E FRESCOR URBANAS NO BAIRRO CAMOBI, SANTA MARIA/RS, EM SITUÇÃO ATMOSFÉRICA DE DOMÍNIO DA MASSA POLAR ATLÂNTICA NO INVERNO
}

\author{
Franciele Francisca Marmentini Rovani ${ }^{3}$ \\ Eduino Rodrigues da Costa ${ }^{4}$ \\ Roberto Cassol ${ }^{5}$ \\ Maria da Graça Barros Sartori6
}

\begin{abstract}
RESUMO
Este trabalho teve por objetivo, analisar o campo termo-higrométrico e a formação de ilhas de calor e frescor no bairro Camobi, Santa Maria-RS, em um dia sob domínio da Massa Polar Atlântica no inverno. Para tal, definiram-se dois transectos móveis (um no sentido N/S e outro no sentido E/W) onde se realizou coletas de temperatura $\left({ }^{\circ} \mathrm{C}\right)$ e umidade relativa do ar $(\%)$ em pontos préestabelecidos e em cinco horários diferentes (09h, 12h, 15h, 18h e $21 \mathrm{~h}$ ). Foram elaborados cartogramas referentes ao campo térmico-higrométrico da área de estudo com o auxílio do aplicativo Surfer for Windows 8.0. Para a análise integrada dos dados elaborou-se o mapa de orientação de vertentes e do uso da terra, por meio do aplicativo Spring 5.0.3. Como resultado destaca-se que o campo termo-higrométrico da área de estudo está condicionado ao movimento aparente do sol, a orientação e exposição das vertentes à entrada de radiação solar e ao uso da terra. Verificou-se também que as ilhas de calor e frescor de magnitude muito forte $\left(9^{\circ} \mathrm{C}\right.$ e $-9^{\circ} \mathrm{C}$, respectivamente), definiram-se melhor nos horários das 18 e 21 horas, quando o contraste de temperatura entre o centro e a periferia do Bairro se acentua, principalmente nesta situação de domínio polar no inverno.
\end{abstract}

Palavras-chave: clima urbano, uso do solo, campo termo-higrométrico, ilhas de calor e de frescor, espaço geográfico.

\footnotetext{
${ }^{3}$ Acadêmica do Curso de graduação em Geografia - Bacharelado da Universidade Federal de Santa Maria.franciele.rovani@yahoo.com.br

${ }^{4}$ Geógrafo, mestre em Geografia pela Universidade Federal de Santa Maria. eduinocosta@gmail.com

${ }^{5}$ Geógrafo, Profo. Dro. do Curso de Graduação e de Pós-Graduação em Geografia da Universidade Federal de Santa Maria. rtocassol@gmail.com

${ }^{6}$ Profa. Dra. do Curso de Graduação e de Pós-Graduação em Geografia da Universidade Federal de Santa Maria. magracas@mail.ufsm.br
} 
ABSTRACT

The objective of this paper is to analyze the thermohygrometric characteristics and the heat and fresh-island formation on Camobi Street in Santa Maria-RS, in a day with Atlantic polar air mass on winter. Therefore, two changeable transect (one in N/ S and other in E/W directions) were determined in which the temperature $\left({ }^{\circ} \mathrm{C}\right)$ and air humidity (\%) were collected in previously established points and in five different times (at 9 am, $12 \mathrm{am}, 3 \mathrm{pm}, 6 \mathrm{pm}$ and $9 \mathrm{pm}$ ). Cartograms related to the thermohygrometric field were accomplished by using Surfer for Windows 8.0. For data analysis, maps of the slope orientation and of the land use by using Spring 5.0.3. The results showed that: the thermo-hygrometric characteristics of the study field are subjected to the solar orientation, and; the slope orientation and exposition are subjected to the beginning of solar radiation and land use. The heat and fresh islands of intense magnitude $\left(9^{\circ} \mathrm{C}\right.$ and $\left.-9^{\circ} \mathrm{C}\right)$, were better defined at $6 \mathrm{pm}$ and $9 \mathrm{pm}$, when the temperature between the center and the surrounding region of Camobi street increased, mainly in the situation of polar control on winter.

Keywords: urban climate, land use, thermo-hygrometric field, heat and freshisland, geographic space.

\section{INTRODUÇÃO}

As transformações nas cidades, decorrentes da ação antrópica sobre o ambiente, constituem a forma mais evidente da modificação da paisagem natural (AMORIM, 2005). A urbanização é um dos fatores significativos que contribui para a artificialização do espaço e para a mudança na qualidade de vida e do meio ambiente.

A influência das formas do relevo, através da hipsometria (SARTORI, 2000; SAYDELLES, 2005), da vegetação (MASCARÓ, 1996; FERREIRA, 2007) e da orientação de vertentes (GEIGER, 1990; MENDONÇA, 1994), atua em conjunto com a ação antrópica por meio da modificação da superfície natural e da introdução de elementos artificiais, interferindo no equilíbrio energético e nos climas locais (SARTORI, 2000; GONÇALVES, 2003). Assim, a interferência constante da ação humana no ambiente urbano, por meio de edificações, pavimentação de ruas, poluição (água e ar), supressão da vegetação e utilização de energias é responsável direta pela formação do clima urbano e seus produtos (ilhas de calor e de frescor, microclimas, topoclimas).

Desta maneira, a substituição de áreas verdes por grande quantidade de construções, que é tanto maior quanto mais se aproxima do centro das grandes cidades (PAZERA JUNIOR, 1976), faz aumentar significativamente a irradiação de calor para a atmosfera em comparação com as zonas periféricas ou rurais, onde, em geral é maior a cobertura vegetal, constituindo-se assim ilhas de calor urbano.

A urbanização, de acordo com Lombardo (1985), Sartori (1986) e Gonçalves (2003) impõe modificações no clima local comprometendo a própria atmosfera da cidade, originando o clima urbano. Esse é um sistema que 
abrange o clima de um dado espaço terrestre e sua urbanização (MENDONÇA; MONTEIRO, 2003) sendo as atividades socioeconômicas urbanas os principais fatores de sua formação.

As diferenças de temperatura existentes entre a cidade e seu entorno, ocasionam diferenças de pressão entre zonas urbanas em que ocorrem as maiores temperaturas $\mathrm{e}$ as áreas periféricas, onde ocorrem as menores temperaturas (OLIVEIRA, 1987; DANNI-OLIVEIRA, 1987; MAGEE; WENDLER, 1999). Essa diferença de temperatura do ar entre o centro da cidade e as áreas periféricas (ilha de calor) acentua-se mais à noite, sob condições atmosféricas de vento calmo e céu limpo, como afirma Spirn (1995, p. 69):

\footnotetext{
Durante a noite, o campo perde calor rapidamente para o céu sem nuvens. A cidade esfria mais lentamente, ela absorveu mais calor, e a irradiação desse calor para o céu é inibida pelas paredes paralelas dos edifícios. Pela manhã, a diferença de temperatura entre a cidade e o campo é mínima e pode mesmo ser eliminada, mas, na metade da tarde, a cidade fica mais quente novamente.
}

Assim sendo, a intensidade das ilhas de calor está associada com a localização geográfica e o tamanho da cidade, com o adensamento humano e urbano. Esses centros urbanos sofrem influência dessa anomalia térmica, resultando no aumento das temperaturas e elevação do índice pluviométrico.

Nesta perspectiva, levando-se em consideração a influência da urbanização e do uso da terra objetivou-se analisar o campo termohigrométrico, bem como a formação de ilhas de calor e de frescor no Bairro Camobi, município de Santa Maria-RS, em um dia sob domínio da Massa Polar Atlântica no inverno.

\section{MATERIAIS E MÉTODOS}

\section{Localização da área de estudo}

No estudo do campo termo-higrométrico, das ilhas de calor e frescor do Bairro Camobi utilizou-se a metodologia dos transectos móveis, a qual consiste na coleta de dados de temperatura e umidade do ar em pontos e horários préestabelecidos. Quanto à coleta dos dados foram estabelecidos dois transectos: um na direção Norte/Sul (N/S) e outro no sentido Leste-Oeste (E/W) (Figura 1).

O Bairro caracteriza-se pela crescente expansão da urbanização, preferencialmente de uso residencial com predomínio de casas, com concentração comercial e prestação de serviços ao longo da RS-509 (Bolfe, 1997). Limita-se ao norte com o Rio Vacacaí-Mirim, a leste com a Base Aérea de Santa Maria e ao sul com o Campus da Universidade Federal de Santa Maria. Possui elevado fluxo de veículos ao longo da RS-509 e apresenta significativa concentração de gramíneas e de vegetação arbórea em sua porção norte (próxima do Rebordo do Planalto) e sul. 


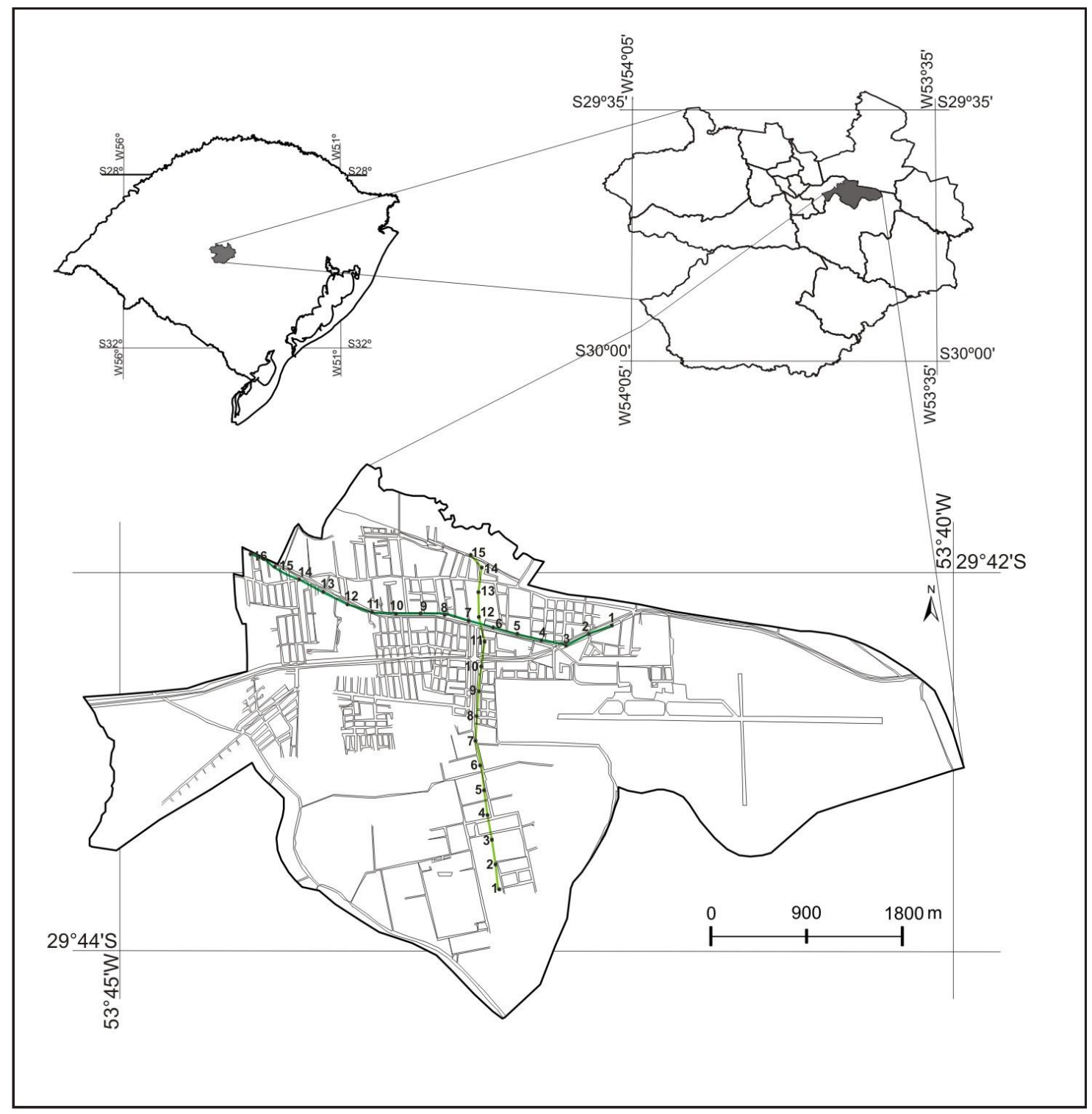

Figura 1. Mapa de localização do Bairro Camobi, Santa Maria-RS.

Fonte. Carta Topográfica de Camobi (MI-2965/2 - SO).

\section{METODOLOGIA}

Em cada um dos transectos foram estabelecidos pontos de coleta, sendo 15 pontos para o transecto norte/sul e 16 pontos para o transecto leste/oeste (Figura 1). Em ambos os transectos adotaram-se uma eqüidistância de 200 metros de um ponto em relação ao outro. Com o auxílio do aparelho GPS (Sistema de Posicionamento Global), marca Garmin-Etrex, foram obtidas as coordenadas planas do sistema UTM (Universal Transversa de Mercator/ Datum Horizontal: Córrego Alegre e Datum Vertical: Marégrafo de Torres) de cada ponto. As coordenadas foram utilizadas na espacialização dos pontos quando da confecção dos cartogramas do campo térmico e higrométrico. 
Estes cartogramas foram confeccionados com o auxílio do aplicativo Surfer for Windows $\AA$ 8.0, utilizando o interpolador Krigagem Ordinária. Na elaboração dos cartogramas do campo térmico foram estabelecidas escalas de cores para os valores de temperatura. As cores frias foram associadas a temperaturas mais baixas e as cores quentes a temperaturas mais altas. Nos cartogramas do campo higrométrico os valores de umidade foram representados utilizando uma variação da cor azul. O azul mais claro foi utilizado para representar os valores de umidade mais baixos e a cor azul escura para os valores de umidade mais altos.

Os dados foram coletados no dia 29 de julho de 2009 em condições de tempo atmosférico sob domínio da Massa Polar Atlântica, em cinco horários (09h, 12h, 15h, 18h e 21h). Os dados foram coletados com o auxílio de dois termômetros digitais (marca Matsutek $($ ) ) a uma altura aproximada de $1,50 \mathrm{~m}$ em relação ao nível do solo. As coletas nos dois transectos foram realizadas simultaneamente nos horários pré-estabelecidos e com duração de no máximo 40 minutos.

A magnitude das ilhas de calor e de frescor foi estabelecida com base em García (1996), em: - fraca magnitude (entre $0{ }^{\circ} \mathrm{C}$ e $2{ }^{\circ} \mathrm{C}$ ); - média magnitude (entre $2{ }^{\circ} \mathrm{C}$ e $\left.4{ }^{\circ} \mathrm{C}\right)$; - forte magnitude $\left(4^{\circ} \mathrm{C}\right.$ e $\left.6{ }^{\circ} \mathrm{C}\right)$ e muito forte magnitude (acima de $6^{\circ} \mathrm{C}$ ).

Com o auxílio do aplicativo Spring 5.0.1 foram elaborados os mapas de orientação de vertentes e de uso do solo. Definiu-se a orientação das vertentes em oito faces: norte, nordeste, noroeste, sul, sudeste, sudoeste, leste e oeste segundo a metodologia proposta por De Biasi et al. (1977).

$\mathrm{Na}$ representação foram utilizadas cores mais quentes (tons de vermelho) para representar as vertentes de orientação norte, leste e oeste, que recebem maior insolação e para as vertentes de orientação sul mais sombreadas, foram utilizadas cores frias (tons de azul). Estabeleceu-se ainda, uma classe específica para as áreas planas mais expostas à insolação direta.

Com base na imagem do Satélite Landsat $-5^{7}$ de 30/06/2009 elaborou-se o mapa de uso de solo. Cinco classes foram definidas para a análise do uso e ocupação do solo: áreas agrícolas e solo exposto, áreas urbanas, campo, florestas e água.

\section{RESULTADOS E DISCUSSÃo}

Para a análise espacial dos dados de temperatura e umidade elaborou-se o mapa de orientação de vertentes que objetiva apontar quais são as áreas que mais recebem insolação. De acordo com Saydelles e Sartori (2007) durante a movimentação aparente do Sol ao longo do ano no Hemisfério Sul, somente nas áreas tropicais o Sol atinge o zênite durante o solstício de verão, e nas áreas equatoriais nos equinócios de primavera e outono. Assim sendo, as áreas localizadas nas regiões subtropicais apresentam menor incidência quanto à insolação anual, pois os raios solares atingem a região formando um ângulo sempre menor que $90^{\circ}$ durante o ano inteiro. Por isso, nas regiões subtropicais austrais as vertentes inclinadas para norte recebem maior insolação do que as vertentes orientadas para sul.

${ }^{7}$ http://www.dgi.inpe.br/CDSR/ 
Desse modo, com a movimentação diária do Sol, a insolação acentua-se diferentemente de leste para oeste, proporcionando o gradativo aquecimento do ar. Assim, as vertentes orientadas para o quadrante leste, recebem a insolação pela parte da manhã e apresentam as temperaturas em elevação; as vertentes orientadas para o quadrante norte recebem intensa insolação ao meio dia, horário em que as temperaturas já são mais altas; as vertentes voltadas para o quadrante oeste recebem a insolação mais intensa pela parte da tarde, cujas temperaturas são mais elevadas, principalmente nos dias de verão; e as vertentes voltadas para o quadrante sul recebem pouca insolação devido à inclinação dos raios solares (Figura 2). Nas áreas planas estes fatos não são observados, pois as mesmas recebem insolação direta em todas as horas do dia.

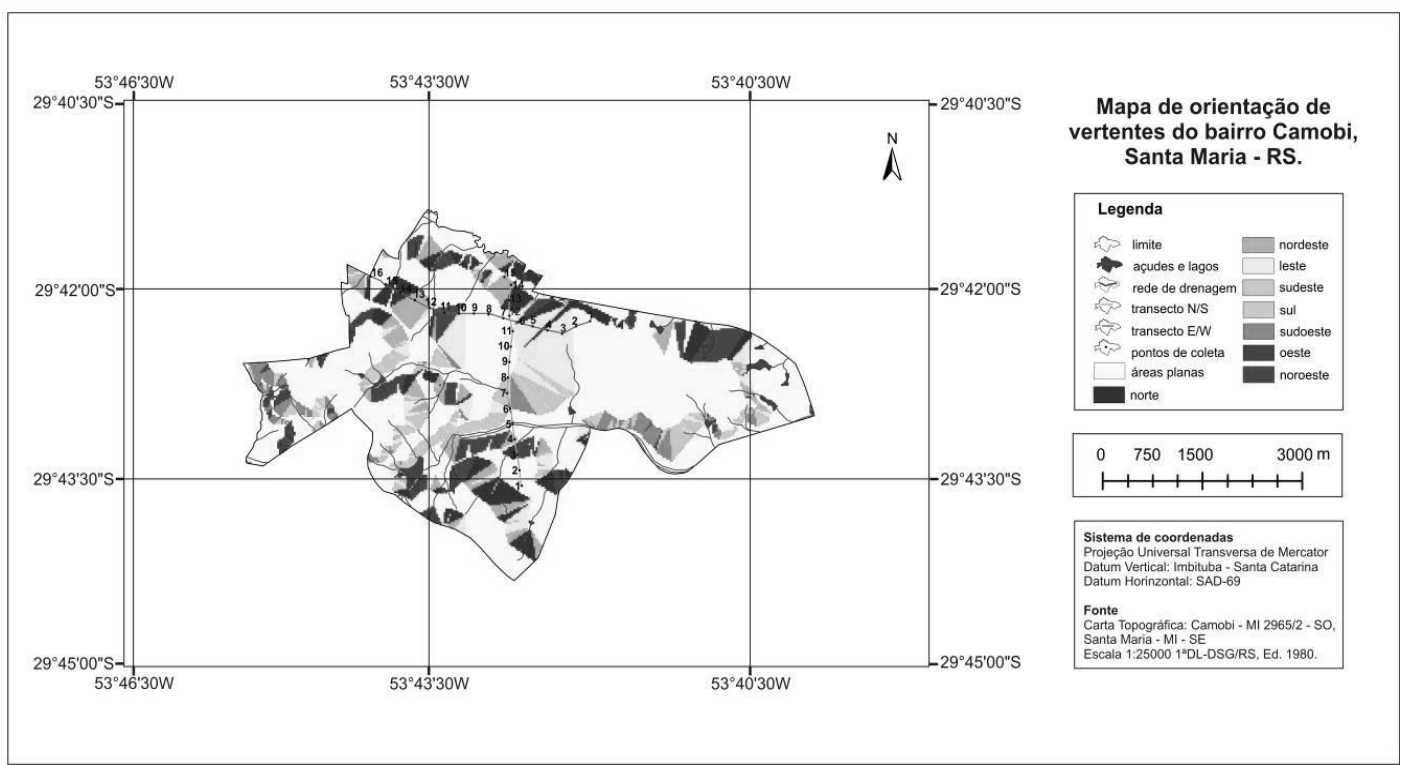

Figura 2. Mapa de orientação de vertentes do Bairro Camobi, Santa Maria-RS. Fonte. Carta Topográfica de Camobi (MI-2965/2 - SO).

Quanto ao mapa de uso da terra (Figura 3), elaborado com o auxílio do aplicativo Spring 5.0.1, foi identificado cinco classes representativas (Tabela 1).

Tabela 1. Classes de uso da terra do Bairro Camobi, Santa Maria - RS

\begin{tabular}{lcc}
\hline Classes de uso da terra & Área (ha) & Percentagem (\%) \\
\hline Água & 335 & 8,47 \\
Áreas urbanas & 875 & 22,14 \\
Solo exposto e agricultura & 846 & 21,40 \\
Campos & 1520 & 38,46 \\
Florestas & 377 & 9,53 \\
\hline
\end{tabular}

Desse modo, pode-se observar que o Bairro está em constante crescimento e desenvolvimento de áreas residenciais, incluídas nas áreas urbanas, apresentando também grande parte de sua área ocupada por campos, solo exposto e agricultura, situados principalmente na periferia. Estas áreas 
verdes contribuem para um ambiente mais sadio e harmonioso, interferindo de maneira direta em alguns fatores ambientais, bem como no conforto térmico.

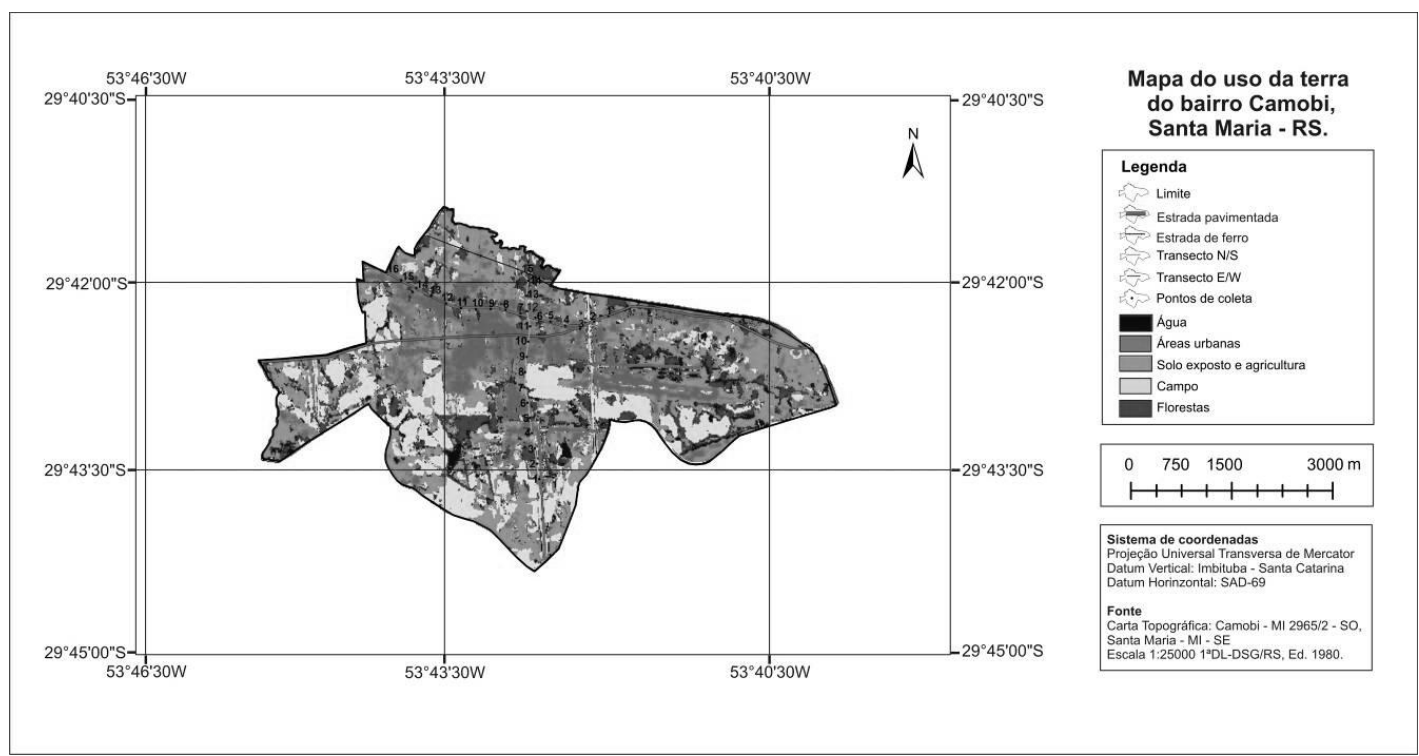

Figura 3. Mapa do uso da terra do Bairro Camobi/Santa Maria - RS.

Fonte. Imagem de satélite LANDSAT-5 (30/06/02009).

Em uma situação de domínio das condições atmosféricas pela Massa Polar Atlântica, temos a estabilidade do tempo atmosférico com céu totalmente limpo o que facilita a entrada de radiação solar na superfície e o conseqüente aquecimento do ar (SARTORI, 1981). Além disso, os ventos fracos do quadrante sul e calmarias verificadas nesta fase contribuem para a formação localizada de ilhas de calor dificultando sua dispersão.

Analisando o campo térmico às 09 horas da manhã (Figura 4A), nota-se que as áreas periféricas ao Bairro estão mais aquecidas. Isso ocorre em função da periferia ser mais aberta à insolação direta do que o núcleo, que nesse horário pode se encontrar sombreado pela presença de prédios e da própria vegetação arbórea. A baixa inércia térmica dos solos rurais em relação à área urbanizada do local conforme destaca Mendonça (1994) pode contribuir para que a periferia se aqueça bem mais rápido.

Nota-se também a presença de duas ilhas de frescor: uma de média magnitude $\left(-3^{\circ} \mathrm{C}\right)$ localizada entre os pontos $7,8,9,10,11$ e 12 e outra de forte magnitude $\left(-6^{\circ} \mathrm{C}\right)$ entre os pontos $1,2,3$ e 4 do transecto leste/oeste.

Os pontos de 1 a 11 do transecto norte/sul mantiveram uma homogeneidade de temperatura em torno de $7^{\circ} \mathrm{C}$. Os pontos 14 e 15 do transecto norte/sul localizados em uma área aberta à insolação se constituíram em uma ilha de calor de forte magnitude $\left(6^{\circ} \mathrm{C}\right)$. Já os pontos 15 e 16 do transecto leste/oeste também localizados, em uma área aberta à insolação direta (Figura 2), se constituíram numa ilha de calor de forte magnitude $\left(5^{\circ} \mathrm{C}\right.$ ). Em relação ao campo higrométrico (Figura $4 \mathbf{B}$ ), verificou-se que a porção nordeste apresentou os menores índices de umidade do ar (inferior a $72 \%$ ), enquanto que os maiores índices foram observados na porção oeste, ao longo do transecto 2 (superior a $78 \%$ ). 

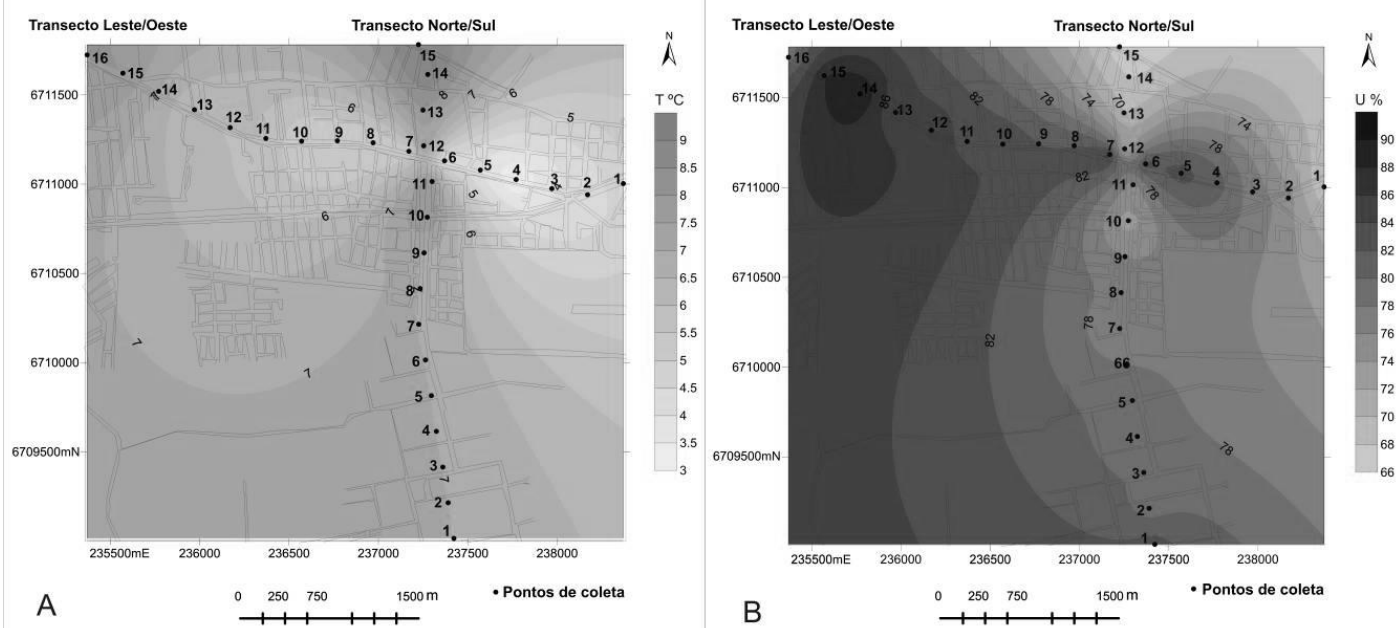

Figura 4. Campo térmico $(A)$ e higrométrico (B) do Bairro Camobi/Santa Maria às 09 horas, sob domínio da Massa Polar Atlântica no inverno.

Às 12 horas as vertentes de orientação norte recebem os maiores índices de insolação aquecendo rapidamente a superfície e o ar em contato. Analisando o campo térmico das 12 horas (Figura 5A) observa-se a presença de três ilhas de calor de forte magnitude (entre $5^{\circ} \mathrm{C}$ e $6{ }^{\circ} \mathrm{C}$ ): uma entre os pontos $13,14 \mathrm{e}$ 15 do transecto norte/sul em uma área aberta à insolação direta, escassa presença de vegetação e com vertentes de orientação norte/nordeste (Figura 2); outra entre os pontos 15 e 16 do transecto leste/oeste também em área aberta à insolação direta e de intensa impermeabilização do solo e outra entre os pontos 9, 10 e 11 do transecto norte/sul em área caracterizada pelo intenso fluxo de veículos e pessoas, pouca presença de vegetação e alta impermeabilização do solo.

Os pontos 4 e 5 do transecto norte/sul constituíram uma ilha de calor de média magnitude $\left(3^{\circ} \mathrm{C}\right)$. Os pontos de 1 a 5 do transecto leste/oeste, situados numa vertente leste (Figura 2), e por isso protegidos da insolação direta, apresentaram as menores temperaturas do horário, se constituindo numa ilha de frescor de forte magnitude $\left(-5{ }^{\circ} \mathrm{C}\right)$. A presença de áreas pouco impermeabilizadas, abertas a ventilação e com a presença de formações vegetais campestres e arbóreo-arbustivas, possibilita a formação de ilhas de frescor uma vez que grande parcela da radiação solar que incide sobre estas superfícies são utilizadas para os processos de evapotranspiração sobrando pouca energia para aquecer o ar.

Ao contrário do campo térmico das 9 horas as áreas mais aquecidas estão localizadas no interior do Bairro e não na periferia. As áreas de menores temperaturas às 12 horas se localizam no sul e leste, justamente onde há maior presença de vegetação (campos, florestas) e pouca aglomeração urbana.

Em relação ao campo higrométrico das 12 horas (Figura 5B), verifica-se que a porção norte e nordeste apresenta os menores índices de umidade do ar (menores que $50 \%$ ) o que corresponde às áreas de maior aquecimento. 
A porção sul e sudeste da área apresentou os maiores índices de umidade, devido principalmente à presença da vegetação e do processo de evapotranspiração que aumenta a umidade no ar.

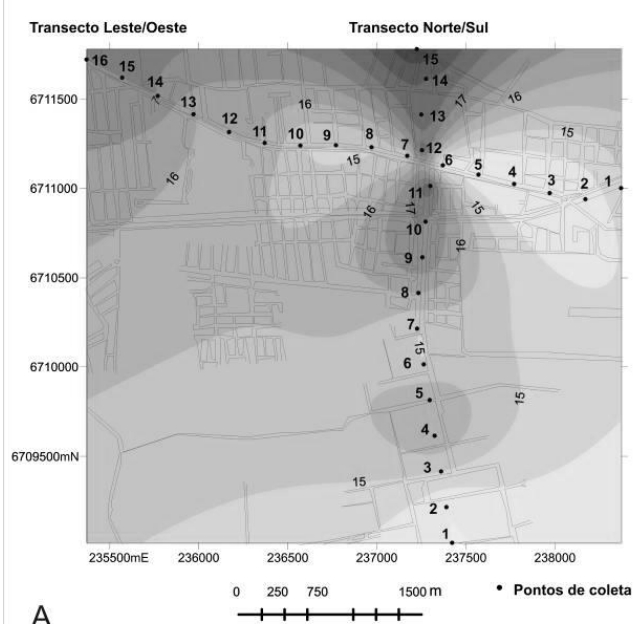

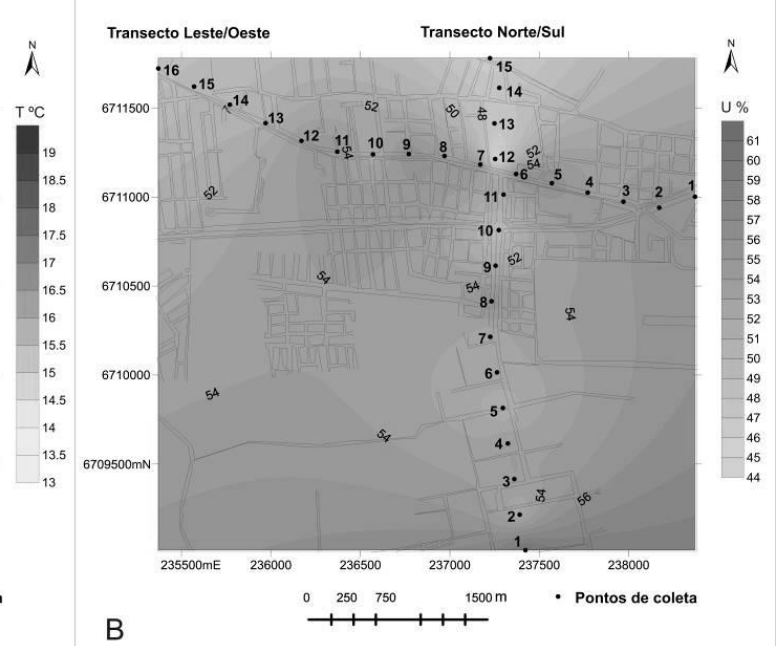

Figura 5. Campo térmico (A) e higrométrico(B) do Bairro Camobi/Santa Maria às 12 horas, sob domínio da Massa Polar Atlântica no inverno.

Às 15 horas o céu apresentava-se limpo, com ventos fracos do quadrante sul. As vertentes voltadas para a porção norte e oeste recebem diretamente a insolação, aquecendo-se mais rapidamente. Em contrapartida, as vertentes voltadas para o quadrante leste e sul recebem menos insolação, aquecendo-se mais lentamente.

Analisando o campo térmico das 15 horas (Figura 6A), verificou-se que os maiores valores de temperatura, situavam-se justamente na porção norte, noroeste, sendo estas áreas que recebem diretamente insolação neste horário.

Nesse horário ocorreram duas ilhas de calor de forte magnitude $\left(5^{\circ} \mathrm{C}\right)$ entre os pontos 12 e 13 do transecto norte/sul (vertente com orientação norte) e 11, 12 e 13 do transecto leste/oeste (vertente com orientação nordeste), em áreas caracterizadas pelo adensamento urbano, escassa presença de vegetação, alta impermeabilização do solo e intenso fluxo de veículos. Nota-se também que todo o sítio urbano está mais aquecido em relação às áreas periféricas.

A porção sul da área de estudo, caracterizada pela presença de gramíneas, vegetação arbórea e arbustiva, baixa urbanização e por isso mais permeável, apresentou as menores temperaturas do horário (15 horas) se constituindo em uma imensa ilha de frescor de forte magnitude $\left(-5^{\circ} \mathrm{C}\right)$.

Quanto ao campo higrométrico (Figura 6B) verifica-se que os menores índices de umidade do ar foram encontrados justamente nas áreas em que a temperatura manteve-se elevada, dada a relação inversa entre temperatura e umidade relativa do ar.

Já os maiores índices de umidade do ar foram verificados na porção sul da área de estudo menos aquecida, caracterizada pela maior presença de vegetação e baixa ocupação urbana do solo. Assim, nesse horário foram registrados os maiores valores de temperatura e os menores índices de umidade do ar. 

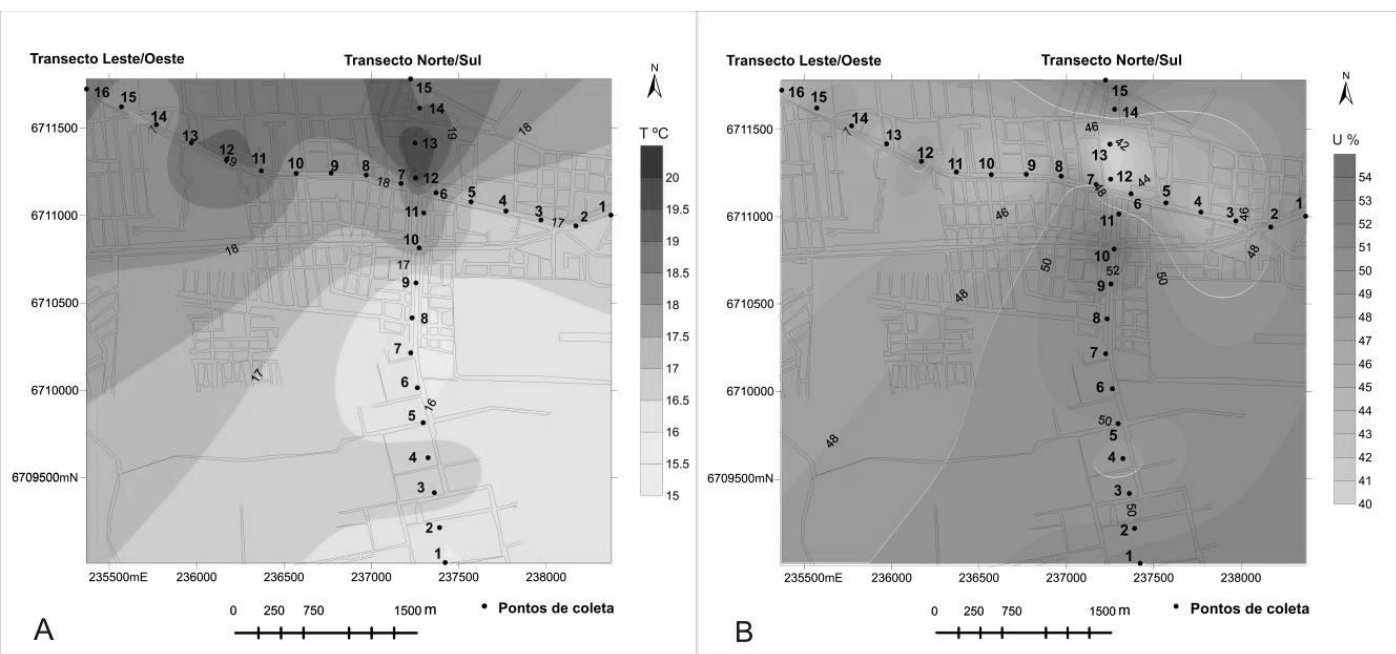

Figura 6. Campo térmico (A) e higrométrico (B) do Bairro Camobi/Santa Maria às 15 horas, sob domínio da Massa Polar Atlântica no inverno.

Às 18 horas devido ao inverno, o balanço positivo de radiação apresentava-se quase nulo. A superfície aquecida devido ao recebimento de calor durante o dia iniciava um lento processo de resfriamento. O campo térmico às 18 horas (Figura 7A) apresentava duas ilhas de calor de magnitude muito forte $\left(9^{\circ} \mathrm{C}\right)$, ambas localizadas ao longo do transecto leste/oeste coincidindo com as áreas de mais intensa circulação de automóveis e forte ocupação urbana. O transecto norte/sul apresentou as menores temperaturas do horário. Os pontos 14 e 15 do transecto norte/sul mais próximos do Rebordo do Planalto se constituíram em uma ilha de frescor de magnitude muito forte ( -9 $\left.{ }^{\circ} \mathrm{C}\right)$.

Os pontos 4 a 10 do transecto norte/sul em área de presença de vegetação arbórea, também se constituíram em uma ilha de frescor de magnitude muito forte $\left(-8^{\circ} \mathrm{C}\right)$. $\mathrm{O}$ transecto leste/oeste apresentou-se bem mais aquecido do que o transecto norte/sul.

De maneira geral pode-se afirmar que a partir das 18 horas melhor se define o contraste térmico entre o núcleo urbano e sua periferia. As ilhas de calor se definem melhor sobre a malha urbanizada e assumem maior magnitude. Pois, na periferia menos urbanizada e com maior presença de vegetação o resfriamento noturno é bem mais rápido, enquanto no núcleo urbanizado, as partículas em suspensão, fumaça e poluentes impedem que o calor armazenado durante o dia pela superfície seja perdido rapidamente para o espaço.

Quanto ao campo higrométrico (Figura 7B), observa-se que os maiores índices foram encontrados ao longo do transecto norte/sul menos aquecido e na porção sul da área de estudo em virtude da maior presença de vegetação e menor adensamento urbano. Já os menores índices foram encontrados ao longo do transecto leste/oeste mais precisamente onde se localizam as duas ilhas de calor. 

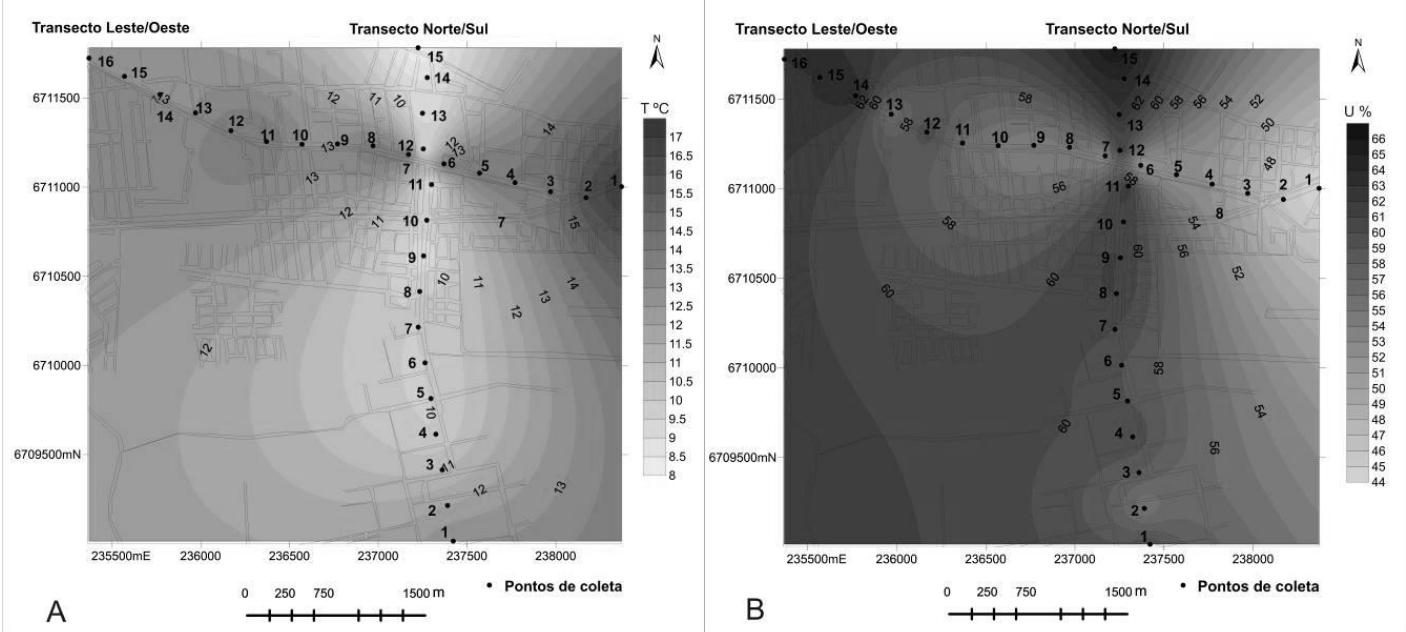

Figura 7. Campo térmico (A) e higrométrico (B) do Bairro Camobi/Santa Maria às 18 horas, sob domínio da Massa Polar Atlântica no inverno.

Às 21 horas, sob condições de céu limpo e calmaria o comportamento térmico foi semelhante ao verificado às 18 horas, principalmente em relação à localização espacial das ilhas de calor e de frescor.

O campo térmico (Figura $\mathbf{8 A}$ ) na porção leste manteve-se mais aquecido, apresentando os maiores valores de temperatura da área de estudo (superior a $9^{\circ} \mathrm{C}$ ), similar ao campo térmico das 18 horas.

Os pontos 8 a 11 do transecto norte/sul definiram uma ilha de frescor de magnitude muito forte $\left(-7^{\circ} \mathrm{C}\right)$. Os pontos 13,14 e 15 do transecto norte/sul, localizados nas proximidades do Rebordo do Planalto, também se constituíram numa ilha de frescor de magnitude muito forte $\left(-8^{\circ} \mathrm{C}\right)$.

Os pontos 10, 11 e 12 do transecto leste/oeste formaram uma ilha de calor de forte magnitude $\left(5^{\circ} \mathrm{C}\right)$, devido ao fluxo de veículos e principalmente pela concentração de edifícios comerciais e residenciais que absorvem o calor mantendo-o armazenado próximo a superfície por mais tempo.

Ainda no transecto leste/oeste, foram verificadas as maiores temperaturas do horário nos pontos 1 e 2, que definiram uma ilha de calor de magnitude muito forte $\left(8^{\circ} \mathrm{C}\right)$.

Com relação ao campo higrométrico (Figura $\mathbf{8 B}$ ) verifica-se que os menores valores de umidade do ar foram registrados na porção leste da área de estudo (inferior a 65\%), justamente nas áreas mais aquecidas do horário.

Os maiores valores de umidade do ar foram registrados no centro das ilhas de frescor localizadas ao longo do transecto norte/sul (superior a 74\%). A porção sul e a porção norte apresentaram-se mais úmidos que a área central em função da presença de vegetação e menos edificações. 

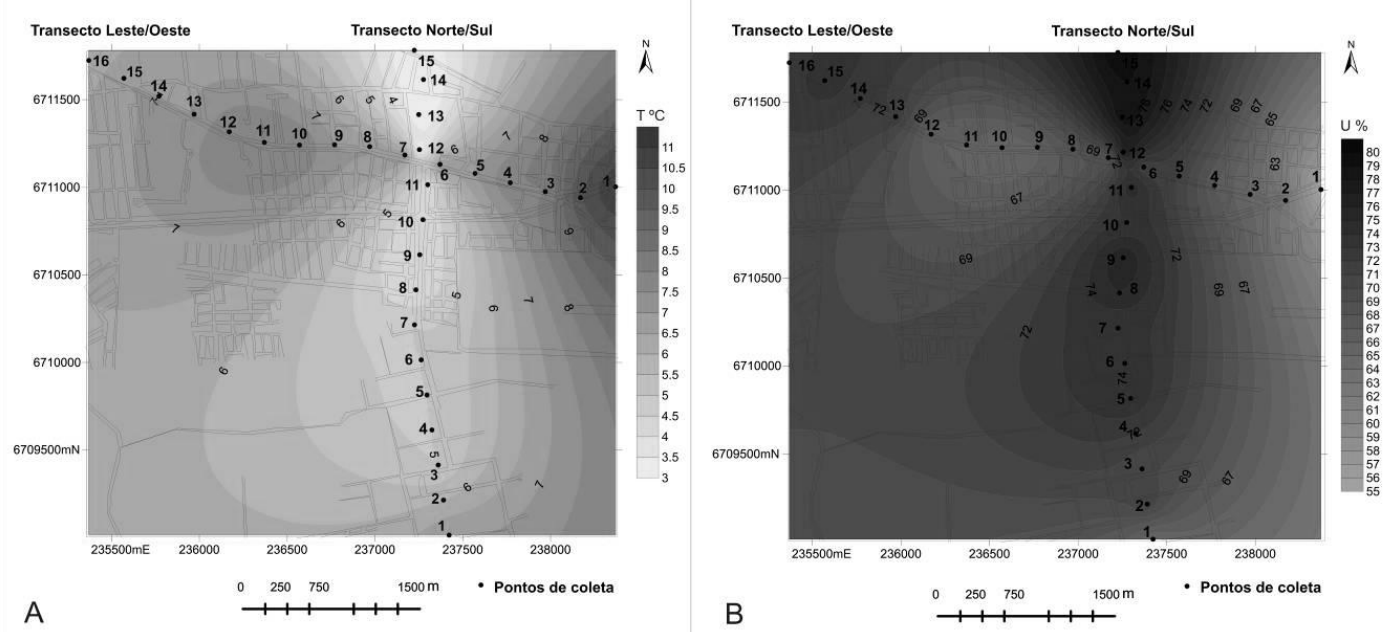

Figura 8. Campo térmico $(A)$ e higrométrico (B) do Bairro Camobi/Santa Maria às 21 horas, sob domínio da Massa Polar Atlântica no inverno.

\section{CONSIDERAÇÕES FINAIS}

A partir do campo termo-higrométrico da área de estudo em um dia sob domínio da Massa Polar Atlântica no inverno, pode-se verificar que o mesmo está condicionado ao movimento aparente diário do sol; da orientação e exposição das vertentes em relação à radiação solar e ao uso da terra.

Fatores geoecológicos, tais como, presença de vegetação arbórea e de campos situados na periferia, constituem-se condicionantes importantes no comportamento dos valores de temperatura e umidade do ar.

Nos horários das 09 e 12 horas a porção central e alguns pontos do transecto leste/oeste demoraram mais para se aquecer, em virtude do menor ângulo dos raios solares que intensificam o sombreamento causado por alguns prédios. As 15, 18 e 21 horas o centro das ilhas de calor localizaram-se nas áreas mais urbanizadas e impermeabilizadas do bairro (ao longo do transecto leste/oeste). As ilhas de frescor se definiram melhor na periferia do bairro, principalmente na porção sul, caracterizada pela presença de campos, florestas, solos expostos e áreas agrícolas.

As ilhas de calor definiram-se melhor nos horários das 18 e 21 horas, sendo que nestes horários, verificaram-se também as maiores amplitudes térmicas entre o centro e a periferia da área de estudo.

\section{Agradecimentos}

À Universidade Federal de Santa Maria pela concessão da Bolsa de Iniciação Científica - FIPE/Sênior durante o período de execução da pesquisa. 


\section{REFERÊNCIAS BIBLIOGRÁFICAS}

AMORIM, M. C. de C. T. Ilhas de calor em Birigui/SP. Revista Brasileira de Climatologia, São Paulo, v. 1, n. 1, p. 121-130, 2005.

BOLFE, S. A. A expansão urbana de Santa Maria, RS: uma avaliação da adequabilidade do uso do solo. 1997, 152f. Dissertação (Mestrado em Geografia) - Departamento de Geografia/FFLCH/USP, São Paulo, 1997.

DANNI-OLIVEIRA, I. M. Aspectos temporo-espaciais da temperatura e da umidade relativa de Porto Alegre em Janeiro de 1982: contribuição ao estudo do clima urbano. 1987. Dissertação (Mestrado em Geografia) Departamento de Geografia/FFLCH/USP, São Paulo, 1987.

DE BIASI. M. et. al. Cartas de orientação de vertentes: confecção e utilização. Cartografia, São Paulo, n. 4, p. 1-12, 1977.

FERREIRA, M. J. et al. Evolução diurna do balanço de radiação na superfície da cidade de São Paulo., Brasil. In: $8^{\circ}$ CONGRESSO IBEROAMERICANO DE ENGENHARIA MECÂNICA. 2007, Cuzco. Anais..., Cuzco/Peru, 2007. p. 1-9.

GARCÍA, F. F. Manual de climatologia aplicada: clima, medio ambiente y planificación. Madrid: Editorial Síntesis. S. A. 1996. 285 p.

GEIGER, R. Manual de microclimatologia - o clima da camada de ar junto ao solo. Lisboa: Fundação Calouste Gulbenkian. 1990. 639 p.

GONÇALVES, N. M. S. Impactos pluviais e desorganização do espaço urbano em Salvador. In: MENDONÇA, F de A.; MONTEIRO, C. A. F. (Orgs.). Clima Urbano. São Paulo: Contexto, 2003. 192 p.

LOMBARDO, M. A. Ilha de calor nas metrópoles: o exemplo de São Paulo. São Paulo: Hucitec, 1985. 244 p.

MAGEE, N.; WENDLER, G. The urban heat island effect at Fairbanks. Alaska. Theoretical and Apllied Climatology. v.64, p.39-47, 1999.

MASCARÓ, L. Ambiência Urbana. Porto Alegre: Sagra-D.C, 1996. 199 p.

MENDONÇA, F. de A. O clima e o planejamento urbano das cidades de porte médio e pequeno: proposições metodológicas para o estudo e aplicação à cidade de Londrina/PR. 1994, 322f. Tese (Doutorado em Geografia) - Departamento de Geografia/UFCLH/USP, São Paulo, 1994.

MENDONÇA, F.; MONTEIRO, C. A. F. Clima urbano. São Paulo: Contexto, 2003. $196 \mathrm{p}$.

OLIVEIRA, P. M. P. de. Indicações para o Planejamento e o Desenho da Forma Urbana Apropriada, à Região Tropical de Clima Quente - Úmido. In: CIÊNCIA PARA OS TRÓPICOS: CONGRESSO BRASILEIRO DE TROPICOLOGIA, 1987, Recife. Anais... Recife: Massangana, 1987, p. 313-319. 
PAZERA. JR, E. A ilha de calor da cidade: fatores e atributos. Boletim Geográfico, Rio de Janeiro, v. 34, n. 249, p. 51-57, 1976.

SARTORI, M.G.B. A circulação atmosférica regional e as famílias de tipos de tempo identificadas na região central do Rio Grande do Sul. Ciência e Natura, Santa Maria, v.3, p. 101-110, 1981.

- Clima e Percepção. 2000. Tese (Doutorado em Geografia) - Departamento de Geografia/UFCLH/USP, São Paulo, 2000. - Modelização do clima urbano de Santa Maria, RS. Ciência e Natura, Santa Maria, v. 8, p. 53-65, 1986.

SAYDELLES, A. P. Estudo do campo térmico e das ilhas de calor urbano em Santa Maria-RS. 2005. 237 f. Dissertação (Mestrado em Geografia) Departamento de Geociências. Santa Maria, 2005.

SAYDELLES, A. P., SARTORI, M. G. B. Análise da insolação direta nas vertentes do Bairro Centro da cidade de Santa Maria-RS. In: SIMPÓSIO BRASILEIRO DE GEOGRAFIA FÍSICA APLICADA, 10., 2007 Santa Maria. Anais... Santa Maria. 2007. p. 1-10.

SPIRN, A. W. O Jardim de Granito: A natureza no Desenho da Cidade. São Paulo: Ed. da USP, 1995. 360 p. 